\title{
1981 budget reverses shift from physical sciences to life sciences
}

Defence research increases set the pace for a $13 \%$ growth in the R\&D budget which President Carter is asking from Congress in 1981. David Dickson reports from Washington

THE Carter administration is seeking to use the 1981 budget to reverse what it sees as a "disturbing trend" in science policy over the past decade and a half, namely a relative decline in funding for research in mathematics and the physical sciences compared to the growth in medical research and life sciences.

Official calculators, for example, show that support for physics dropped by $13.5 \%$ in real terms between 1967 and 1980, and for mathematics by $16.7 \%$ over this period. In contrast funding for the life sciences increased by $19 \%$, and the environmental sciences experienced a real growth of $33.7 \%$.

Moves to correct this imbalance - for example within the budget of the National Science Foundation, which plans to give particular emphasis to increasing support for fields such as computer science figure prominently in a budget request also characterised by a growth in research projects jointly sponsored by the federal government and private industry, and dominated by significant increases in Defense Department expenditure on research.

Overall President Carter, who singled out basic research in his budget message to Congress last Monday, as one of the few areas meriting increased support, is asking Congress for a $13 \%$ growth in support for research and development, including a $12 \%$ increase in funds for basic research.

Given an officially-estimated increase in cost of $9 \%$ (a figure some claim to be overly-optimistic) this will mean real growth in 1981 of $4 \%$ and $3 \%$ respectively in the total R\&D and basic research expenditures.

Much of this is directly due to increases in the military research budget. Military sponsored R\&D is planned to grow by
$20.2 \%$ - including funds for research in very high speed integrated circuits and for full scale development of the MX intercontinental ballistic missile - and military support for basic research will be up by $21.4 \%$.

The growth in the budget of the National Aeronautics and Space Administration will be comparatively smaller, at $9.8 \%$ for overall R\&D (taking into account an extra $\$ 300$ million being requested for 1980 ), and $11.5 \%$ for space science.

However Dr Robert Frosch, Administrator of NASA, calls it a "good start" to the decade, with growth in all areas of the budget, at least compared to last year when the extra costs of the space shuttle meant no new space science programme starts.

Included in NASA's request for 1981 are funds for a gamma ray observatory, and an operational National Oceanic Satellite System (NOSS), which will build on the success of last year's SEASAT mission, and will be jointly funded with the Department of Defense and the National

\section{Energy department announces 'slip' in laser fusion}

THE Department of Energy has decided to allow "slippage" in construction work on the NOVA neodymium glass laser and irradiation facility at the University of California's Lawrence Livermore Laboratory in order to ensure a "more balanced" programme of advanced driver studies for inertial confinement fusion technology.

Construction work on NOVA started last year, and over $\$ 80$ million will have been spent on the project by the end of the current fiscal year. However in its budget request for 1981, the department has included no extra construction money although it says that construction work will continue. Final costs are estimated at $\$ 136$ million.

In contrast to inertial confinement, the budget for magnetic fusion research has been increased by $13.5 \%$, to a total of $\$ 403.6$ million. This figure includes a $40 \%$ increase for development and technology, and a $36 \%$ increase for applied plasma physics.

\section{NSF to fund laboratory renovations}

THE National Science Foundation is planning to introduce a new programme to help universities renovate out-dated research facilities. Federal funding for the first year of the programme will be $\$ 14.3$ million, and the money will be awarded on a matching-grant basis, with academic institutions matching federal support with funds from non-federal sources.

According to NSF director Dr Richard Atkinson, the money will not be available to buy new instrumentation or equipment, or to restock libraries, but is intended to be spent on the improvement of existing facilities, on the basis that outdated facilities "bring less than optimal return on the investment of federal dollars for support of research". A statement from the Office of Science and Technology Policy says that the cost-sharing programme will focus on "the nation's most productive research universities".

\section{Defense Department increases} university research support

THE Department of Defense plans to increase by about $25 \%$ in 1981 its support of both research and development in general, and basic research in particular, carried out by US universities.

Figures released by the Office of Management and Budget indicate that DOD support for university research is expected to increase only $10.5 \%$, from $\$ 401$ million to \$443 million, part of an overall $9.5 \%$ increase in federally-funded university research predicted to reach a total of $\$ 4.6$ billion.

However Dr Frank Press told a press briefing that according to $\mathrm{Dr}$ William Perry, Defense Under-Secretary for Research and Technology, new programmes planned by the DOD will mean that the actual increase is more than twice this rate. Overall support for basic research by the Defense Department is proposed to increase by $21 \%$ in 1981.

\section{Energy research: less for nuclear, more for coal}

PRESIDENT Carter is recommending to Congress that the Department of Energy's support for nuclear fission research be reduced by $22 \%$ - largely by abandoning work on the Clinch River liquid metal fast breeder reactor - but that there be a $34 \%$ increase for research into the uses of coal.

Despite a continued failure to persuade Congress to accept his arguments for killing the Clinch River project, the President is recommending that support for LMFBR research be cut from $\$ 615$ million to $\$ 300$ million. In addition, he is also suggesting that research be terminated on the gas cooled fast breeder concept, currently supported at a level of $\$ 26$ million a year and on the thermal reactor fuel cycle.

Reflecting a growing political interest in coal as a source of energy, the budget recommends coal research be increased from $\$ 779$ million to $\$ 1047$ million. 
Oceanic and Atmospheric Administration.

Funds for basic biomedical research at the National Institutes of Health are scheduled to be raised by $6.2 \%$ to $\$ 1.7$ billion. Congress is likely to add a little to this figure, but it will be nowhere near as substantial as in the last decade.

Of the various biomedical research institutes, the National Institute of Environmental Health Sciences is slated for the biggest increase $-15 \%-$ and the Institute of General Medical Sciences 6\%, while the two largest institutes, the National Cancer Institute and the National Heart Lung and Blood Institute, are planned to grow $0.7 \%$ and $3.8 \%$.

In the National Science Foundation, which is planned to increase its basic research budget by $18.8 \%$, special emphasis will be given to supporting research in the physical sciences and engineering. For example, the budget request allows for a $16 \%$ increase for physics research, $28 \%$ for computer research, and $28 \%$ for electrical, computer and systems engineering research.

In contrast, support for biological, behavioural and social sciences is scheduled to grow by only $9.3 \%$ - scarcely above the expected level of cost inflation.

Prominent in the NSF's budget request is increased funding for research projects jointly sponsored with industry, a move prefigured in the President's innovation

BUDGET REOUEST FOR FISCAL YEAR 1981 (in \$ million)

\begin{tabular}{|c|c|c|c|c|c|c|}
\hline \multirow[t]{2}{*}{ Agency } & \multicolumn{3}{|c|}{ R\&D obligations 1} & \multicolumn{3}{|c|}{ Basic research obligations } \\
\hline & $\begin{array}{c}1981 \\
\text { request }\end{array}$ & $\begin{array}{c}\text { \%increase } \\
1980 / 81\end{array}$ & $\begin{array}{l}\% \text { of } \\
\text { total }\end{array}$ & $\begin{array}{c}1981 \\
\text { request }\end{array}$ & $\begin{array}{c}\text { \%increase } \\
1980 / 81\end{array}$ & $\begin{array}{l}\% \text { of } \\
\text { total }\end{array}$ \\
\hline Defense & 16,565 & 20.2 & 45.7 & 523 & 21.4 & 10.3 \\
\hline NASA & 5,617 & $9.8^{2}$ & 15.6 & 581 & $8.3^{3}$ & 11.5 \\
\hline Energy & 5,106 & $3.8^{4}$ & 14.1 & 593 & 13.4 & 11.7 \\
\hline \multicolumn{7}{|l|}{ Health and } \\
\hline Human Services & 4,011 & 6.0 & 11.1 & 1,840 & 6.5 & 36.3 \\
\hline (NIH) & & & & 1,704 & 6.2 & 22.6 \\
\hline \multicolumn{7}{|l|}{ National } \\
\hline Science Foundation & 1,056 & 17.7 & 3.9 & 952 & 16.9 & 18.8 \\
\hline Agriculture & 786 & 5.8 & 2.2 & 324 & 12.1 & 6.4 \\
\hline \multicolumn{7}{|l|}{ Environment } \\
\hline Protection Agency & 445 & 7.3 & 1.2 & 19 & 36 & 0.4 \\
\hline Interior & 415 & -1.0 & 1.1 & 78 & 2.6 & 1.5 \\
\hline Commerce & 379 & 2.2 & 1.0 & 36 & 28.6 & 0.7 \\
\hline Others & 1,756 & 16.0 & 4.8 & 127 & 39.5 & 2.5 \\
\hline Total & 36,136 & 13 & 100 & 5,074 & 12.0 & 100 \\
\hline
\end{tabular}

1. Obigations is the amount of money committed to a programme

2. Takes into account extra $\$ 300$ million requested for 1980

3. Excludes cost of spacecraft

4. Excludes energy research money expected from energy security

message to Congress last November. For example, support for small business innovation and industrial technology will grow from $\$ 7.4$ million to $\$ 18.2$ million, and for industry/university cooperative research from \$7 million to \$20 million.

The most dramatic manifestation of this new linkage is agreement between the NSF and several major oil companies to jointly sponsor a 10-year, $\$ 700$ million ocean margin drilling programme (Nature 24 January page 321) using the ship Glomar Explorer as a drilling base.

But the Foundation will also be developing a comparable programme of automotive research, which will receive initial federal funding of $\$ 20$ million in 1981. The estimated costs of $\$ 1$ billion over ten years will be shared between government and the automotive industry.
Part of these funds will go to three large demonstration projects for coal liquefaction and gasifaction processes, carried out on a cost-sharing basis with private industry.

\section{$\$ 15$ million allocated for new UN science fund}

THE Carter administration proposes in its budget request to contribute $\$ 15$ million in 1981 to an interim fund to support scientific activities in the Third World agreed at the UN Conference on Science and Technology for Development (UNCSTD) in Vienna last year. The size of the contribution is less than had initially been hoped for, and some feel this may reflect US unhappiness about the reorganisation of science policy machinery within the UN.

\section{High energy physics keeps its head just above water}

DESPITE previous agreement that funding for high energy physics would do no more than keep pace with the general rise in costs, the administration has responded to recent complaints by the physics community and agreed to a $10.5 \%$ increase in the budget for 1981, officially representing a $1.5 \%$ growth above the predicted $9 \%$ inflation rate.

This increase will bring the HEP budget to a total outlay of $\$ 350$ million in 1981 , a sum which includes the final year of funding for Fermilab's energy saver/ doubler project, and the initiation of the tevatron colliding beam facility at the same site.

A $9.5 \%$ increase is being requested for nuclear physics. In addition to supporting the continued construction of the National Superconducting Cyclotron Laboratory at Michigan State University, this money will also allow construction work to begin on a tandem accelerator system at the Argonne National Laboratory.

\section{Gamma ray observatory \\ preferred to comet mission}

PLANS for a gamma ray observatory were given funding preference by the National Aeronautics and Space Administration over a proposal to initiate work on a joint flight to the comets Halley and Tempel 2 because it offers "a more fundamental mission", according to NASA Administrator Dr Robert Frosch.

The administration is asking Congress for $\$ 19.9$ million to begin work on the observatory in 1981, a project actively canvassed for by space scientists for several years as a successor to earlier gamma ray satellites. The observatory is now scheduled to be launched from the space shuttle in 1985.

Dr Frosch told a press briefing that there was a "reasonably good chance that the much-delayed space shuttle, still officially scheduled for launch this summer, would have its first flight by the end of the year, although there was a likelihood that it would have to be postponed until the first quarter of 1981. In addition to a 1981 budget request $\$ 800$ million more than originally planned for the shuttle, NASA is also asking Congress for an extra $\$ 300$ million for the current year to cover unexpected costs, largely the result of problems with fixing insulating tiles to the shuttle's surface.

\section{NIH to reduce training grants}

THE National Institutes of Health is to reduce the number of training grants for postdoctoral students in 1981 by $7 \%$ from the 1980 level of 10,175 . The most significant reduction will be in individual grants, which will drop $33 \%$ from 1626 to 1080 . Institutional grants will be reduced by $2 \%$ to 8390 . At the same time the value of stipends will be increased by about $5 \%$, and this comes on top of a $30 \%$ increase agreed for 1980 . In 1981 stipends will range from $\$ 14,040$ to $\$ 17,892$ a year, compared to $\$ 10,000$ to $\$ 13,000$ in 1979 .

The total value of training grants issued by NIH will be reduced by $7.4 \%$, from $\$ 176$ million to $\$ 163$ million. At the same time the administration has agreed to keep the number of new competitive research grants at about 5000 . 